Olga Fedunina*

\title{
О некоторых тенденциях развития и изучения криминальной митературы в современной России (краткий обзор)
}

DOI: http://dx.doi.org/10.12775/LC.2021.023

\begin{abstract}
Аннотация: В статье Аается обзор основных тенденций развития и изучения российской криминальной митературы новейшего периода. Обосновывается необходимость жанрового подхода к исследованию ее поэтики. Намечаются связи с жанровыми традициями мировой криминальной митературы и ее соцреалистического варианта. Аинию полицейского романа, ориентированную больше на этическую проблематику, продолжает А. Маринина. ОАнако в целом этот жанр оказывается заслонен крутым детективом. Еще один ведущий криминальный жанр, „расследование жертвы”, фактически замещается Аругой модемью, где сюжет определяется противостоянием человека и государственной (ими мафиозной) системы. Выделяется также ведущая роль „авантюрного расследования” (термин Н. Кириленко), которое реализуется в произведениях разного художественного уровня (Б. Акунин, А. Аонцова и Ар.). Очевидно, его рационально-игровая природа в большей степени соответствует эпохе постмодернизма.
\end{abstract}

Ключевые слова: криминальная митература, полицейский роман, крутой детектив, „расследование жертвы”, „авантюрное расследование”.

* Ольга Федунина

Кандидат филологических наук, старший научный сотрудник отдела „Литературное наследство”, Институт мировой литературы им. А.М. Горького РАН. Научные интересы: литературные сны как художественная форма, жанры криминальной литературы, теория жанров, нарратология.

E-mail: fille.off@gmail.com | ORCID: 0000-0001-6874-248X. 


\title{
New Trends in Crime Literature: Progress and Research in Russia Today (A Short Overview)
}

\begin{abstract}
The article gives an overview of the main trends in the development and study of Russian crime literature of the recent period. We argue that it is necessary to adopt a genre approach in the study of its poetics / approach to study its poetics. We seek parallels with genre traditions of world crime literature and its socialist realistic variant. We discuss the police novel, focused primarily on ethical issues, continued by A. Marinina. However, in general, this genre is overshadowed now by an action detective. Another leading criminal genre, "investigation of the victim," is actually replaced by another model, where the plot is determined by the opposition between the individual and the state (or mafia) system. The undoubtably leading role of the "adventurous investigation" (by N. Kirilenko's term) is realized in the works of B. Akunin, D. Dontsova, etc. We believe that its rational game nature is more convenient in the postmodern era.
\end{abstract}

Key words: crime literature, police novel, action detective, "victim investigation", "adventurous investigation"

оворя о новейшей российской криминальной митературе, следует, прежде всего, иметь в виду следующие моменты: 1) эта область привлекает внимание не столько теоретиков, сколько историков митературы и лингвистов (если речь идет именно о научной традиции), что приводит к недостаточной разработанности жанрового подхода неотрефлексированности того, какие криминальные жанры существуют и что вообще поА ними понимается. Характерный пример - Аиссертация Натальи Филистовой, гАе рассматривается „детективный нарратив” в целом, без Аифференциации по отдельным жанрам криминальной китературы (Filistova 2007); 2) произошеАший изнутри китературного процесса своего рода разрыв с общемировыми тенденциями, поскольку криминальная митература советского периода подчинялась идеологическим задачам и развивалась весьма специфически. Аругой резкий поворот связан с возобновлением уже в 1990-е годы ориентации на западные образцы с переосмыслением сложившихся традиций. Остановимся на этих аспектах подробнее, не ставя, однако, своей целью Аать всеобъемлющий обзор, что было бы невозможно в рамках короткой статьи.

Несмотря на огромное, казалось бы, количество работ, посвященных обозначенной теме, исследований собственно поэтики криминальной митературы и ее отдельных жанров совсем немного. Причины именно такого развития научной традиции Аетально прослежены в аргументированном обзоре Натальей Кириленко - автором диссертации Жанровый инвариант и генезис классического детектива, которая во многом восполняет возникшую макуну (Kirilenko 2017: 4-20); см. также ее неАавно вышедшую монографию (Kirilenko 2020). В российских исследованиях с незначительными вариациями сохраняется стереотипная классификация, во многом 
порожденная изАательской практикой (Titareva 2015: 119-125): женский детектив (Ischchuk-Fadeyeva 2010: 112-131; Gavrikova 2016: 245-254), психологический Аетектив (Leskov 2005), иронический детектив (Leonov 2013: 222-226; Kovaleva 2010: 108-113; Klenova 2014: 117-123), боевик и т.А. В Аанном скучае ее можно назвать „жанровой” мишь в кавычках, поскольку к жанру как научному понятию это не имеет отношения, а использование соответствующего слова, как правияо, никак не аргументируется авторами работ.

Особенно „повезцо” в отечественной традиции понятию „тримеер”. Сразу оговорюсь, что Аалее я буду использовать иную жанровую номинацию - „расследование жертвы”, - по типу основного героя, который Аолжен распутывать направленные против него преступления. Основные константы этого жанра, которые уАалось выделить при анализе текстов, принадлежащих к разным национальным традициям, - геройнепрофессионал, вынужденно участвующий в расследовании преступлений, которые угрожают его безопасности и жизни; негативное отношение к игре, которую зАесь, в отличие от кАассического детектива, ведет только преступник; единоличное финальное противостояние с убийцей; неспособность потенциальной жертвы полностью установить истину, Аля чего обычно необходимо саморазоблачение убийцы (Fedunina 2012: 130-141).

Необходимость обозначить четкие границы этого жанра возникла из того, что поА „тримлером” фактически понималось все - и ничего. Само понятие оказалось совершенно Аискредитировано, к примеру, следующим определением из Аитературной энциклопедии терминов и понятий:

сенсационный, захватывающий боевик $[\ldots]$ с искусно организованным, напряженным сюжетом и стремительным развитием действия. [...] Характерные образцы Т. - романы А. Кристи (Аесять негритлт, 1943; Свидетель обвинения, 1953), С. Кинга (N[ikolyukin] 2003: 1097).

Приведенное определение ничуть не проясняет, чем же отличается тримлер от боевика, а названные в качестве примера романы Агаты Кристи явмяются чем угодно, только не „сенсационным, захватывающим боевиком” (который в сознании читателей обычно ассоциируется скорее со стрельбой и кровавыми разборками). Татьяна Скокова и вовсе относит тример только к области кино, называя в качестве его китературного аналога „уголовный роман” (Skokova 2009: 97).

ПодхоА к этой проблеме Николая Вольского, создателя известного сайта „КАассический Аетектив: поэтика жанра"1, отличается разве что противопоставлением „Аетектива” и „тримлера” по наличию/отсутствию в основе сюжета „загадки”, причем преступление вообще не признается в качестве необходимого признака „детектива”. В таком скучае, однако, границы и вовсе размываются, а предмет исследования теряется. Тот же подход сохраняется в монографии Петра Моисеева Поэтика детектива (Moiseyev 2017).

Вследствие всего сказанного изучаются, по большей части, отдельные авторы (к примеру, Борис Акунин (Bobkova 2010; Kazachkova 2015) и Александра Маринина

\footnotetext{
1 Классический детектив: поэтика жанра; http://detective.gumer.info/.
} 
(Mela 2000: 93-103; Savkina 2005: 139-156; Trofimova 2002) - как своего рода вершины современного отечественного „детектива”), темы и мотивы, типология героев или „Аетективный Аискурс” (что особенно характерно Аля лингвистических исследований), но не поэтика криминальной митературы в комплексном рассмотрении, как особая система жанров. Зарубежный или российский материал - здесь не играет такой уж большой роли. Это, условно говоря, проблема внешняя, связанная с особенностями рецепции и изучения криминальной митературы в России. Аюбопытно, что ее развернутых обзоров не так уж много: помимо справочника Современный отечественный детектив (Yeremina [\&] Yaroshenko 2006), стоит назвать книги не научные, но относящиеся скорее к области митературной критики или к эссеистике (Razin 2000; Tukh 2006).

Так нужен ми вообще жанровый подхоА при изучении криминальной митературы? Или можно вполне обойтись без этих „досужих выдумок” исслеАователей, ибо читателю безразлично, что и как мы назовем, Аишь бы получить удовольствие от развития сюжета и его развязки? Следуя обозначенной могике, легко прийти к тотальному размыванию границ. К примеру, в очень интересном исследовании массовой митературы, проведенном Марией Черняк с позиций „социологии чтения”, произведения Марининой преАставлены как синтез полицейского, криминального, производственного и мюбовного романов - и все это названо женским детективом по гендерной принаАмежности автора и главной героини (Chernyak 2009: 266). Разумеется, переА исслеАовательницей стояли другие задачи - не столько рассмотреть поэтику конкретных

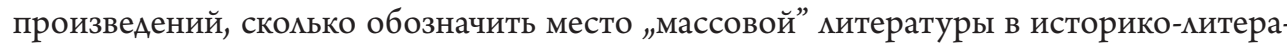
турном процессе и на книжном рынке. Но в итоге не столько проясняется, сколько теряется всякая индивидуальность материала. Не учитывается также такой момент, как возможность объединения автором произведений разных жанров в рамках одной серии.

В рамках прочитанного студентам историко-филологического факультета РГГУ курса по поэтике криминальной митературы (Fedunina 2014: 61-78) мной был проведен простой эксперимент: слушателям курса преАложено сАелать сравнительный анализ „мужского” и „женского” вариантов полицейского романа с опорой на трехмерную модель жанра, выделенную Михаилом Бахтиным (Bakhtin 2000а; 2000b; 2000c; 2003: 140-155; Tamarchenko 2011: 69-76). Такой подход к жанру позвомяет охватить все основные уровни поэтики: субъектно-речевую организацию, мир героя (пространственно-временную организацию, сюжет и т.А.), характер соотношения межАу мирами героя и автора/читателя (в криминальной митературе он связан с возможностью восстановления нормы после завершения расследования). Материалом послужили Розанна Пера Валё и Май Шевамль и Мужские игры Александры Марининой. При анализе учитывались, в частности, типы героев, особенности преступления, метода и хода расследования, пространственно-временной и субъектной организации, возможности восстановления нормального течения жизни после раскрытия преступления. Сопоставление привело к неожиАанному аля участников результату: привычное Аля них сочетание „женский Аетектив” оказалось совершенно неработающим инструментом, тогАа как во всех основных элементах структуры выявилось очевидное сходство швеАского романа, гАе герой-сыщик мужчина, и русского, гАе главной героиней является женщина. Аело не в гендерных особенностях, но в законах 
жанра - в Аанном случае полицейского романа, - которые вцияют на поэтику конкретных его образцов.

Аругая проблема, которая также во многом опредемяет судьбу криминальной митературы в России, связана скорее с ее внутренними особенностями развития. В соответствии с илеологической установкой на борьбу с врагом внешним и внутренним в митературе советского периода развивались, по сути, только шпионский роман и жанр, который Абрам Вулис назвац „производственным романом из жизни милиции” (Vulis 1978: 258). Шпионский роман быи представлен в Авух модификациях: роман об иностранном резиденте (яркие образцы - серия Аьва Овацова о майоре Пронине, Аилогия Олега Шмемева и Владимира Востокова Ошибка резидента и Возвращение резидента), а также роман о советском разведчике (И один в поле воин Юрия АольАМихайлика, серия Юлиана Семенова о Штирлице/Максиме Исаеве, Земля, до востребования Евгения Воробьева, Сильные духом Амитрия Медведева). „Милицейская” повесть и роман преАставмены произведениями Аркадия ААамова (Аело „пестрых”; трилогия Инспектор Аосев, состоящая из трех романов - Злым ветром, Петля, На свободное место), Юлиана Семенова (Петровка, 38) и Аругими, не столь известными, но сохраняющими типичные жанровые черты: расследование, которое ведет команда профессионалов; пересечение криминальной и частной сюжетных миний; особый тип жертвы, вызывающей сочувствие героев-сыщиков и читателя. Отличительной особенностью по сравнению с западным полицейским романом было обязательное наличие идеологической минии, порой тормозящей развитие криминального сюжета (введение в текст пространных мекций милицейского начальства, негативная оценка индивидуальной инициативы героя в расследовании и т.п.). В ряде текстов акцент делался не на этих элементах, а на этической проблематике, что позволяет говорить о выходе за пределы собственно криминальной митературы с ее концентрацией на преступлении и его расследовании, но не на глубинных причинах, по которым оно совершается (Жестокость и Испьтательный срок Павла Нилина, Эра милосердия Вайнеров).

ОтАельного разговора заслуживают произведения Вайнеров, в которых переосмысливается канон соцреалистической милицейской митературы и происходит переориентация на „вечные”, идущие еще от Ф.М. Аостоевского вопросы о сущности и соотношении преступиения и наказания как таковых. Меняются в связи с этим типы героя-сыщика и преступника. В повести Гонки по вертикали инспектор Стас Тихонов и вор Алексей Аедушкин по кличке Батон преАстают как, с одной стороны, взаимно искмючающие Аруг Аруга „противополюсы” (Vayner [\&] Vayner 1974: 39) и несомненные антагонисты (первый хочет „жить правильно”, а второй „хорошо”); с Аругой же - как герои-Авойники, которые сами осознают свою неразрывную связь. В повести в равной степени преАставлены их позиции, причем в форме внутренней речи героев случай, неАопустимый Аля нормативной милицейской митературы, гАе автор не Аолжен искушать читателя слишком поАробным изображением преступника и его мировоззрения. (К примеру, А. ААамов в позАней реАакции изымает из сюжета Аела „пестрых” минию, связанную со шпионом Питом, где позиция преступника была преАставлена именно с внутренней точки зрения). Вор Аолжен сидеть в тюрьме - вот выражение этой нормы в словах ГАеба Жеглова из другого произведения Вайнеров, романа Эра милосердия. Казалось бы, расклаА вполне закономерный. Но АеАушкин в Гонках по вертикали, зверь, который сам загоняет себя в мовушку (мотив, восходящий к традициям 
русской классической митературы, к Преступлению и наказанию Аостоевского), - такой вор парадоксально становится равным противником и неразАельно неслиянным близнецом протагониста.

По сути, в повести Вайнеров преАставлены Ава альтернативных мировоззрения, оба из которых не укладываются в обычную норму; потому Тихонов и Батон в равной мере не выдерживают испытание на соответствие обычной жизни с ее усредненными потребностями и благами. Оба не имеют шанса когАа-мибо обзавестись войлочными тапками как символом обывательского мира, в котором они не находят своего места. ГАавное отличие - именно в следовании исконному нравственному принципу воровать нельзя, который отстаивает Тихонов и отрицает АеАушкин-Батон. Противостояние Аля обоих заканчивается трагически: почти смертельным ранением Аля Тихонова (читатель так и остается в неведении, останется ми герой живым), Аля Батона же навсегда утраченной возможностью снова обрести статус человека, а не преступника - загнанного волка. Собственно расследование, поиск чемодана, украденного у иностранца, который сам оказывается вором и контрабандистом, совершенно очевиАно заслоняется Аругим вопросом, куда более важным Аля авторов и героя-протагониста. Это вопрос, отсылающий к заглавию повести, вопрос о способности проехать по стене ради того, чтобы уравновесить бессмысленным, казалось бы, поступком обывательскую озабоченность только материальными благами. Аля Батона с его воровской системой ценностей вопрос о возможности и необходимости такого поступка Ааже не стоит, впрочем, как и дмя представмяющей в повести „нормальный” мир Аены - бывшей возмюбленной Тихонова. Но Аля героя-протагониста метафорические гонки по вертикали становятся и смыслом, и еАинственно возможной формой существования. Так меняется еще одна константа криминальной митературы: мотив жертвенности оказывается связанным не с жертвой преступления в юридическом смысле, а с образом сыщика.

Как представмяется, именно этой минии наследует затем уже в постсоветский период Александра Маринина, связь которой с традицией соцреализма отмечалась Ю.О. Чернявской (Chernyavskaya 2006: 99-105). В таких романах из серии о Каменской, как Убийца поневоле, Шестерки умирают первыми, Не мешайте палачу, образы убийц и жертв неоднозначны, не могут быть безоговорочно отнесены к ценностным полюсам добра или зма. В целом это вписывается в общую традицию полицейского романа как жанра криминальной митературы (Kirilenko [\&] Fedunina 2010: 17-32; Kirilenko 2017: 209-230). Вспомним в этом контексте „испытание на человечность” сотрудников милиции в повестях Павла Нилина, а также амбивалентный образ Гцеба Жеглова, наставника главного героя-сыщика в Эре милосердия Вайнеров - примеры, возможно, выходящие за рамки собственно милицейской митературы советского периода, но переосмысмяющие ее константы. Вот круг этических вопросов, с которыми сталкивается главная героиня Анастасия Каменская (и читатель): имеет ми право на месть отец, еАинственного сына которого без всякой причины убили подростки просто потому что он оказался „первым встречным” (Убийца поневоле)? Аостойна ми сочувствия бывшая баскетболистка с неудавшейся мичной жизнью, которая становится марионеткой в играх преступников и милиции (Мужские игры)? И т.А.

В жанровой палитре современной российской криминальной митературы выАеляется также „авантюрное расследование”, которое было определено в качестве 
самостоятельного жанра Натальей Кирименко (Kirilenko 2012: 80-95) (традиционная номинация „иронический детектив”, как и „женский детектив”, не явмяется научным понятием, отражающим жанровую специфику этого явления). ВеАя свою историю от Эмимя Габорио, Мориса Аеблана, созАавшего уникальный образ сыщика и преступника в лице авантюриста Арсена Аюпена, „авантюрное расследование” продолжает развиваться и в наши Ани. ОАним из ярких образцов в новейшей русской митературе явмяется Аюбовница смерти Бориса Акунина, где мы встречаем инвариантного Аһя этого жанра авантюрного сыщика с его Аюбовью к игре и переодеваниям, но, в отмичие от сыщика в классическом детективе, не обладающего монополией на знание истины. Эраст Петрович здесь отнюдь не единственный субъект, который ведет расследование, к тому же, он побеждает в финальном поединке с преступником благодаря лишь чистой случайности - повороту колеса рулетки. Симптоматично, что герой сам упрекает себя в том, что не может предотвратить гибель многочисленных жертв:

Наши засеАания все больше напоминают фарс, но смеяться не хочется. Слишком много т-трупов. Я таскаюсь в этот нелепый кмуб уже три недели, а результат нулевой. Нет, что я говорю! Не нулевой - отрицательный! У меня на глазах погибла Офелия, Аорелея, ГАлевский, Сирано. Я не смог их спасти (Akunin 2004: 188-189).

Отсюда проистекает мишь частичное восстановмение нормального течения жизни после завершения расследования, что опять же разительно отличается от кольцевой структуры классического Аетектива.

Аругие известные российские авторы, которые работают с этим жанром: Аарья Аонцова, создательница серий Аюбительница частного сыска Ааша Васииева, Евлампия Романова. Следствие ведет дилетант; Виктория Пиатова (Ритуал последней брачной ночи); Татьяна Полякова (Капкан на спонсора, Все в шоколаде).

Еще оАна особенность российской криминальной митературы - своего рода жанровые подмены, обусловленные, очевидно, и социокультурными причинами, и требованиями книжного рынка. Так, в полицейском романе (за исключением ряда произвеАений Марининой, о чем шла речь выше) разрушается одна из необходимых констант жанра - соблюдение процедуры, в том числе в юридическом смысле (ср. с одним из вариантов жанровой номинации - police procedural) (Dove 1982). В итоге Кошмар на улище Стачек Анарея Кивинова больше соответствует структуре крутого детектива, hard-boiled fiction: совершенно не случайно повествователь иронически замечает, что оАин из главных героев, Кивинов, осматривает машину жертвы, нарушая все имеющиеся инструкции по проведению осмотра места происшествия. Характерный А^я крутого Аетектива сюжетообразующий мотив мести героя-одиночки, который вынужАен своими силами добиваться справеАливости, кежит в основе романа АнАрея Константинова Адвокат из серии Бандитский Петербург (экранизирован, как почти все упомянутые в этой статье тексты). По меткому замечанию Бориса Туха, 1990-е годы в России с их атмосферой „вседозволенности, продажности и безнаказанности” порожАают героя нового типа - одиночку, который своими силами пытается вершить справедливость, не становясь при этом на сторону ни силовых структур, ни преступного мира (Tukh 2006: 119). 
„Расследование жертвы”, представленное в зарубежной традиции такими романами, как Винтовая лестница (Some Must Watch) Этель Аины Уайт, Щепка (Sliver)

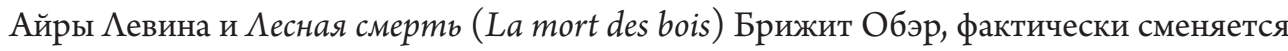
Аругой жанровой моделью, где основу сюжета составцяет противостояние человека и системы. ГАавная особенность - потенциальной жертве противостоит не преступник как отдельная мичность, а государственная машина. Герой, как правило, поневоле мешает планам спецслужб (становится случайным свидетелем, слишком много знает и думает). Эта модель особенно популярна в американской традиции: в качестве примеров можно вспомнить знаменитое Аело о пеликанах (The Pelican Brief) Ажона Гришема и Синдром (Syndrome) Ажона Кейза. Система может быть и чисто криминальной, мафиозной. Из российского материала назову Чеченскую марионетку и Херувима Полины Аашковой, Богиню прайм-тайма Татьяны Устиновой. Оговорюсь, что парадоксальным образом структура „расследования жертвы” определяет „неудачный”, по мнению Петра Моисеева (Moiceyev 2017: 45), роман Бориса Акунина из серии об Эрасте Фандорине Весь мир - театр, гАе герой действует уже не как авантюрный сыщик, природа которого определяется удовольствием от расследования как игры с преступником и свидетемями. Расследуя цепь покушений, направленных против актрисы, в которую он влюблен, герой совершает фатальные ошибки, попадает в мовушки и сам становится объектом игры со стороны убийцы, подобно потенциальной жертве. Мы видим, что изменение мотивировки, по которой сыщик ведет расследование, на вынужАенную (спасение жизни возмюбленной), немедленно отражается на его успешности в этой роли и всем развитии сюжета. То же самое повторяется в Аругом позАнем романе из этой серии, Одинокий парус, гАе Фандорин принимает на себя несвойственную ему роль мститемя за убитую возмюбленную.

Подводя краткие итоги всему сказанному, еще раз подчеркну, что современные тенденции развития российской криминальной митературы демонстрируют смещенные жанровые ориентиры, равно как проблема ее изучения именно в жанровом аспекте остается не вполне отрефлексированной и решенной. Традиции советского периода оказались, в сущности, прерванными: полицейский роман, который продолжала разрабатывать Александра Маринина, очевидно, сменяется крутым детективом. „Расследование жертвы” так и не сумело сформироваться и развиться в чистом виде, его место занимает иная модель, описывающая противостояние человека и преступной государственной системы. Зато на первый план выдвигается „авантюрное расслеАование”, которое реализуется в текстах разного художественного уровня. ПослеАнее, очевидно, как нельзя кучше соответствует общему игровому характеру митературы эпохи постмодернизма.

\section{Библиография}

Akunin, Boris 2004. Lyubovnitsa smerti. Moskva: Zakharov.

Bakhtin, Mikhail Mikhailovich 2000a. „Epos i roman (O metodologii issledovaniya romana)” W: Mikhail Mikhailovich Bakhtin. Epos i roman. Sost. Sergey G. Bocharov, Sankt-Peterburg: Azbuka. 
— 2000b. „Formy vremeni i khronotopa v romane: Ocherki po istoricheskoy poetike”. W: Mikhail Mikhailovich Bakhtin. Epos i roman. Sost. Sergey G. Bocharov. Sankt-Peterburg: Azbuka.

— 2000c. „Problema rechevykh zhanrov”. W: Mikhail Mikhailovich Bakhtin. Avtor i geroy. K filosofskim osnovam gumanitarnykh nauk. Sost. Sergey G. . Sankt-Peterburg: Azbuka.

_ ( pod maskoy) 2003. Formal'nyy metod v literaturovedenii. Moskva: Labirint.

Bobkova, Nataliya Georgiyevna 2010. Funktsii postmodernistskogo diskursa v detektivnykh romanakh Borisa Akunina o Fandorine i Pelagii. Dis. kand. filol. nauk: 10.01.01 Ulan-Ude.

Chernyak, Mariya Aleksandrovna 2009. Massovaya literatura XX veka. Moskva: Flinta.

Chernyavskaya, Yuliya 2006. „K zhanrovomu opredeleniyu detektivov A. Marininoy”. Vestnik TGPU Ser. Gumanitarnyye nauki (filologiya) 8 (59): 99-105.

Dove, George N. 1982. The Police Procedural. Ohio: Bowling Green.

Fedunina, Ol'ga Vladimirovna 2012. „Sledovatel-zhertva v kriminalnoy literature: k voprosu o tipologii geroya i zhanra”. Novyj filologicheskij viestnik 2 (21): 130-141.

Fedunina, Ol'ga Vladimirovna 2014. „Zhanry kriminalnoy literatury: spetskurs dla studentov filologicheskikh spetsyalnostey". Novyy filologicheskiy vestnik 4 (31): 61-78.

Filistova, Natalya Yurevna 2007. Struktura $i$ semantika detektivnovo narrativa (na materiale tekstov anglijskikh $i$ russkikh rasskazov): dis. kand. filol. nauk: 10.02.20. Tyumen.

Gavrikova, Irina Yurevna 2016 „Natsionalnye prioritety w zhenskom detektivye”. W: Nacjonalnyje kody v ewropejskoj literature XIX-XXI wiekow. Nizhnyj Novgorod: Izdatelstvo Nizhnegorodskogo Universiteta.

Ischchuk-Fadeyeva, Nina I. 2010 „Zhenskij detektiv kak zerkalo russkoj pieriestroyki”. Woprosy literatury 5: 112-131.

Yeremina, Irina Vasil'yevna [\&] Yelena Viktorovna Yaroschenko (avt.-sost.) 2006. Sovremennyj otechestviennyj detektiv: bibliogr. ukazatel. Moskva: Paschkov dom.

Kazachkova, Anna Vladimirovna 2015. Zhanrovaya strategiya detektivnykh romanov Borisa Akunina 1900 - nachala 2000-kh gg.: dis. kand. filol. nauk: 10.01.01. Nizhny Novgorod.

Kirilenko, Natal'ya Natanovna 2012. „«Avantyurnoye rassledovaniye» ili klassicheskiy detektiv”. Novyy filologicheskiy vestnik 2 (21): 80-95.

— 2017. Zhanrovyy invariant i genezis klassicheskogo detektiva. Dis. kand. filol. nauk: 10.01.08. Moskva.

— 2020. Klassicheskiy detektiv kak zhanr kriminal'noyliteratury: invariant i genezis. Moskva, Yekaterinburg: Kabinetnyy uchenyy.

[\&] Ol'ga Vladimirovna Fedunina 2006. „Klassicheskiy detektiv i politseyskiy roman: k probleme razgranicheniya zhanrov". Novyy filologicheskiy vestnik 3 (14): 17-32.

Klenova, Yuliya Viktorovna 2014. „Problema seriynosti v ironicheskikh detektivakh Dar'i Dontsovoy”. W: Buranok Oleg Mikhaylovich (red.). Zonal'naya konferentsiya literaturovedov Povolzh'ya. Kazan': Kazanskiy (Privolzhskiy) federal'nyy-universitet.

Kovaleva, Mariya A. 2010. „Sovremennyy ironicheskiy detektiv v gendernom aspekte”. W: Zoya Yanovna Selitskaya (red.). Ot teksta k kontekstu. Ishim: izd-vo IGPI im. P.P. Yershova.

Leonov, Vasiliy Aleksandrovich 2013. „Ironicheskiy detektiv kak osoboye diskursivnoye prostranstvo". Nauchno-pedagogicheskiy zhurnal Vostochnoy Sibirimagister Dixit 4 (12): 222-226.

Leskov, Sergey Vladimirovich 2005. Leksicheskiye i strukturno-kompozitsionnyye osobennosti psikhologicheskogo detektiva. Dis. kand. filol. nauk: 10.02.04. Sankt-Peterburg.

Mela, Elen 2000. „Igra chuzhimi maskami: detektivy Aleksandry Marininoy”. Filologicheskiye nauki 3: 93-103.

Moiseyev, Petr 2017. Poetika detektiva. Moskva: Izdatel'skiy Dom VSHE.

N[ikolyukin], Aleksandr Nikolayevich 2003. „Triller”. W: Aleksandr Nikolyukin (red.). Literaturnaya entsiklopediya terminov i ponyatiy. Moskva: NPK Intelvak. 
Razin, Vladimir Mikhaylovich 2000. V labirintakh detektiva. Ocherki istorii sovetskoy i rossiyskoy detektivnoy literatury KHKH veka. Saratov. URL: http://litresp.ru/chitat/ ru/R/razinvladimir/v-labirintah-detektiva/1 [26.10.2017].

Savkina, Irina 2005. „Istoriya Asi Kamenskoy, kotoraya khotela, da ne smogla... (natsional'nyye osobennosti russkogo feminizma v detektivakh A. Marininoy). Gendernyye issledovaniya 13: $139-156$.

Skokova, Tat'yana Aleksandrovna 2009 „Spetsifika massovoy literatury v epokhu postmodernizma”. Vestnik VGU. (Filologiya. Zhurnalistika) 2: 95-100.

Tamarchenko, Natan Davidovich 2011. «Estetika slovesnogo tvorchestva» Bakhtina i russkaya religioznaya filosofiya. Moskva: Izdatielstvo Kulaginoy.

Titareva, Larisa Dmitriyevna 2015. „Knigoizdaniye kak faktor razvitiya zhenskoy prozykontsa XX nachala XXI v.." Zhenshchina v rossiyskom obshchestve 2 (75): 119-125.

Trofimova, Yelena I. (red.) 2002. Tvorchestvo Aleksandry Marininoy kak otrazheniye sovremennoy rossiyskoy mental'nosti. Moskva: INION RAN.

Tukh, Boris 2006. Krutyye muzhchiny i krovozhadnyye zhenshchiny. Kto yest' kto v russkom detektive?. Tallinn: Izd-vo „KPD”.

Vayner, Arkadiy [\&] Georgiy Vayner 1974. Gonki po vertikali. Moskva: Molodaya gvardiya. Vulis, Abram 1978. „Poetika detektiva”. Novyy mir 1: 244-258. 